\title{
Deleted in malignant brain tumor 1 is a novel prognostic marker in colorectal cancer
}

\author{
HEAE SURNG PARK ${ }^{1 *}$, BYUNG CHANG KIM ${ }^{2 *}$, HYUN YANG YEO ${ }^{3}$, KYUNG-HEE KIM $^{3}$, \\ BYONG CHUL YOO $^{3}$, JI WON PARK ${ }^{4}$ and HEE JIN CHANG ${ }^{5}$
}

\author{
${ }^{1}$ Department of Pathology, Gangnam Severance Hospital, Yonsei University College of Medicine, Seoul 06273; \\ ${ }^{2}$ Center for Colorectal Cancer, Research Institute and Hospital, National Cancer Center; ${ }^{3}$ Research Institute, \\ National Cancer Center, Goyang-si 10408; ${ }^{4}$ Department of Surgery, Seoul National University College of Medicine, \\ Seoul 03080; ${ }^{5}$ Department of Pathology and Center for Colorectal Cancer, Research Institute and \\ Hospital, National Cancer Center, Goyang-si 10408, Republic of Korea
}

Received October 19, 2017; Accepted February 20, 2018

DOI: 10.3892/or.2018.6287

\begin{abstract}
The gene deleted in malignant brain tumor 1 (DMBT1) encoding a large scavenger receptor cysteine-rich protein was originally identified based on its deletion in a brain tumor cell line. The DMBT1 protein is involved in mucosal immune defense, epithelial differentiation and tumor suppression. In the present study, the clinicopathologic significance of DMBT1 protein expression in stool and tissue samples of colorectal cancer (CRC) patients was evaluated. Western blot analysis of fecal DMBT1 was performed for patients with CRC $(n=177)$, colorectal adenoma $(n=61)$, inflammatory bowel diseases (IBDs; $n=54$ ) and healthy individuals as the control group $(n=151)$. Immunohistochemical analysis of tissue expression of DMBT1 was performed in 385 primary CRC tissues. Fecal DMBT1 expression was higher in CRC and IBD patients than in healthy controls or adenoma patients $(\mathrm{P}<0.0001)$, but not significantly different between IBD and CRC or between adenoma and healthy control groups. In CRC patients, fecal DMBT1 expression was not associated with the tumor stage or site. The sensitivity of fecal DMBT1 analysis for CRC was $50 \%$, while the specificity and positive predictive value were 86.8 and $81.3 \%$, respectively. Immunohistochemical expression patterns of DMBT1 in CRC tissues varied from loss to overexpression. Loss of expression was observed in $4.7 \%$ (18 out of 385 cases) and significantly associated with lymph node metastasis $(\mathrm{P}=0.016)$, distant
\end{abstract}

Correspondence to: Dr Hee Jin Chang, Department of Pathology and Center for Colorectal Cancer, Research Institute and Hospital, National Cancer Center, 323 Ilsan-ro, Ilsandong-gu, Goyang-si, Geyonggi-do 10408, Republic of Korea

E-mail: heejincmd@ncc.re.kr

*Contributed equally

Key words: colorectal cancer, prognosis, deleted in malignant brain tumor 1 metastasis $(\mathrm{P}=0.013)$, advanced stage $(\mathrm{P}=0.026)$, and higher histologic grade $(\mathrm{P}=0.033)$. In addition, DMBT1 loss was an independent poor prognostic factor for cancer-associated death (hazard ratio, 2.272; $\mathrm{P}=0.015$ ) and disease recurrence (hazard ratio, 2.689; $\mathrm{P}=0.009$ ). In conclusion, fecal DMBT1 has limited value as a diagnostic biomarker, while the tissue expression of DMBT1 may serve as an efficient prognostic marker for CRC. Furthermore, DMBT1 may have a role in the progression of CRC.

\section{Introduction}

Colorectal cancer (CRC) is the third most common cancer type worldwide (1) and the second most common one in Korea (2). Early diagnosis of CRC is critical to improve oncological outcomes and reduce medical expenses (3). In this study, identification of CRC-specific biomarkers may be useful for diagnosis, prognostication or prediction of therapeutic responses. The biomarkers for CRC identified to date are limited to serum carcinoembryonic antigen levels, mutations of KRAS, NRAS or BRAF and microsatellite instability in CRC tissues. Previous studies by our group reported fecal calgranulin B as a candidate maker for CRC diagnosis. However, calgranulin B was additionally detected in the stool of inflammatory bowel disease (IBD) patients $(4,5)$. In a subsequent study aimed at determining a complementary fecal marker for CRC or IBD, deleted in malignant brain tumors 1 (DMBT1) was incidentally identified in stools of CRC as well as IBD patients [Yoo et al (unpublished data)].

DMBT1 is located on chromosome 10q25.3-q26.1 (6) and encodes three secretory glycoproteins, specifically, DMBT1 protein, salivary agglutinin (DMBT1 ${ }^{\mathrm{SAG}}$ ) and lung glycoprotein-340 (DMBT1 $\left.{ }^{\mathrm{gp} 340}\right)$. DMBT1 ${ }^{\mathrm{SAG}}$ and DMBT1 ${ }^{\mathrm{gp} 340}$ secreted from the salivary gland and respiratory tract, respectively, share identical peptide sequences (7) and monoclonal antibody cross-reactivity (8). The DMBT1 protein is involved in mucosal innate immunity via binding to various pathogens and host molecules, including surfactant protein, immunoglobulin A and complement component 1q (9). However, upon secretion into the extracellular matrix, DMBT1 triggers 
terminal differentiation of epithelial cells $(10,11)$. DMBT1 is mainly synthesized in the trachea, lung, small intestine, salivary gland and stomach (12). Expression of the protein is increased in gastrointestinal epithelium of patients with IBD (13) and Helicobacter pylori-associated gastritis (14).

Due to its repetitive genomic structure, DMBT1 is susceptible to genomic instability (15). Frequent homozygous deletion of DMBT1 was initially reported in medulloblastoma and glioblastoma (6), as reflected by the designated name 'deleted in malignant brain tumor'. In subsequent studies, deletion and/or loss of mRNA expression were observed in esophageal, gastric, colorectal, lung and breast cancers (16-18), supporting the theory that DMBT1 is a tumor suppressor gene. Infrequent mutation of DMBT1 has been reported in astrocytic tumors (19). In addition, upregulation of DMBT1 has been reported in specific glioblastomas (20) and carcinomas of the stomach (21) and lung (22). These diverse observations imply complex roles of DMBT1 in carcinogenesis. To clarify the specific functions of DMBT1 in various cancer types, studies focusing on its clinicopathological impact are required. The present study investigated the diagnostic utility of fecal and tissue expression of DMBT1 in CRC along with its clinicopathological and prognostic significance.

\section{Materials and methods}

Stool sample preparation and patients. Initially, a liquid chromatography-mass spectrometry (LC-MS) analysis of DMBT1 in stool from IBD patients $(n=3)$ was performed, which was extended to various groups of colorectal disease (IBD, CRC and colorectal adenomas). The analysis was performed using two sets: Development and validation. A total of 184 patients were enrolled in the developing (test) set (CRC, $n=81$; adenoma, $n=32$; IBD, $n=20$; and control, $n=51$ ), while the validation set included 256 individuals $(C R C, n=93$; adenoma, $\mathrm{n}=29$; IBD, $\mathrm{n}=34$; and control, $\mathrm{n}=100$ ) from May 2007 to December 2009. Colonoscopy was performed with preparation and sedation according to individual patient characteristics. CRC and colorectal adenoma were diagnosed using colonoscopy and histopathology. Histopathological diagnosis was performed by one pathologist (HJC) according to the World Health Organization classification (23) and the 6th edition of the Tumor-Nodes-Metastasis classification of the American Joint Committee on Cancer (24). Advanced adenoma (AA) were defined as polyps of $>1 \mathrm{~cm}$ in size, villous histopathology, high-grade dysplasia or carcinoma in situ (25). IBD cases included ulcerative colitis $(n=35)$, Crohn's disease $(n=12)$ and IBD, unclassified $(n=7)$ and those were diagnosed based on patient symptoms, laboratory and colonoscopy parameters and histopathological features (26-29). Colonoscopy revealed negative findings in the control group. The persons with an incomplete colonoscopy, or hyperplastic polyps, or inflammatory polyps were excluded from this study.

Stool samples were collected prospectively prior to bowel preparation. Proteins were extracted from $0.1 \mathrm{~g}$ of stool in $0.3 \mathrm{ml}$ PBS containing protease inhibitors via vigorous vortexing, followed by centrifugation at $12,000 \mathrm{x}$ g for $10 \mathrm{~min}$ at room temperature. The supernatant was collected without disturbing the pellet and used for western blotting and LC-MS analyses, in accordance with previous studies $(4,5)$.
SDS-PAGE and LC-MS analysis. Stool proteins from IBD patients were measured using Bicinchoninic Acid Protein Assay kit (Pierce; Thermo Fisher Scientific, Inc., Waltham, MA, USA). Equivalent amounts of stool protein $(10 \mu \mathrm{g})$ were electrophoresed on 4-12\% Bis-Tris Protein Gel (Invitrogen; Thermo Fisher Scientific, Inc.), then fixed in a fixer solution (40\% methanol, $10 \%$ acetic acid) for $10 \mathrm{~min}$ and stained using a Colloidal Blue Staining kit (Invitrogen; Thermo Fisher Scientific, Inc.), according to the manufacturer's instructions. Gel slices containing stool proteins from IBD patients were excised, destained with $50 \%$ acetonitrile in $0.1 \mathrm{M}$ ammonium bicarbonate and dried in a SpeedVac concentrator (Eppendorf, Hamburg, Germany) at room temperature. The dried gel pieces were immersed in $30 \mu \mathrm{l}$ sodium bicarbonate solution $(25 \mathrm{mM}, \mathrm{pH} 8.8)$ containing $50 \mathrm{ng}$ trypsin (Promega Corp., Madison, WI, USA) at $37^{\circ} \mathrm{C}$ overnight. Samples were desalted using Zip-Tips C18 (EMD Millipore, Billerica, MA, USA) and dissolved in $10 \mu 12 \%$ acetonitrile in $0.1 \%$ formic acid. Analysis was performed using a linear ion trap mass spectrometer system (LTQ-XL; Thermo Electron Corp., San Jose, CA, USA) at the Facility of Omics Core Laboratory, National Cancer Center (Goyang, Korea). Peptide separation was performed on an Agilent 1100 system (Agilent Technologies, Santa Clara, CA, USA). A 3- $\mu 1$ sample of the peptide mixture was injected onto a C18-PepMap column (150 mm; inner diameter, $75 \mu \mathrm{m}$; LC Packings, San Francisco, CA, USA), and separated with a gradient of $5-50 \%$ acetonitrile in $0.1 \%$ formic acid over $60 \mathrm{~min}$. The spray voltage was set at $+1.7 \mathrm{kV}$ and capillary temperature at $200^{\circ} \mathrm{C}$. The capillary voltage was set at $+20 \mathrm{~V}$, the tube lens voltage at $+100 \mathrm{~V}$ and the auxiliary gas at zero. Full scan experiments were performed on the linear ion trap mass spectrometer in the mass/charge range of 150-2,000. Systematic MS/MS experiments were performed by changing the relative collision energy and monitoring the intensities of the fragment ions. All MS/MS samples were analyzed using the SEQUEST algorithm v.27, rev. 11 (Thermo Fisher Scientific, Inc.). SEQUEST was set up the SwissProt (ftp:// ftp.ebi.ac.uk/pub/databases/uniprot/knowledgebase) and IPI human databases (ftp://ftp.ebi.ac.uk/pub/databases/IPI/ current) assuming trypsin as the digestion enzyme. A fragment ion mass tolerance of $1.00 \mathrm{Da}$ and parent ion tolerance of 1.2 Da were used for the SEQUEST search.

Western blot analysis. Equivalent amounts of stool protein $(10 \mu \mathrm{g})$ as determined by a Bicinchoninic Acid Protein Assay kit (Pierce; Thermo Fisher Scientific, Inc.) were subjected to SDS-PAGE (4-12\% Bis-Tris Protein $\mathrm{Gel})$. After electrophoresis, the proteins were transferred to polyvinylidene difluoride membranes (EMD Millipore), followed by blocking via incubation in $1.5 \%$ non-fat dried milk (Bio-Rad Laboratories, Inc., Hercules, CA, USA) and $1 \mathrm{mM} \mathrm{MgCl}{ }_{2}$ in Tris-buffered saline containing $1 \%$ Tween-20 for $2 \mathrm{~h}$ at $4^{\circ} \mathrm{C}$. Membranes were incubated for $2 \mathrm{~h}$ at room temperature with primary antibody against DMBT1 (1:1,000, cat. no. sc-80616; Santa Cruz Biotechnology, Inc., Dallas, TX, USA), washed for $3 \times 15$ min with blocking solution, and incubated with diluted goat anti-mouse Ig human ads-horseradish peroxidase (HRP)-conjugated secondary antibody $(1: 10,000$, cat. no. 1010-05; Southern Biotech, Birmingham, UK) for $1 \mathrm{~h}$ 
at room temperature. This step was followed by washing with blocking solution (3x15 min), incubation with WEST-ZOL ${ }^{\circledR}$ plus chemiluminescence reagent (iNtRON Biotechnology, Gyeonggi, Korea) for $1 \mathrm{~min}$, at room temperature and exposure to X-ray film (Kodak Blue XB-1; Eastman Kodak, Rochester, NY, USA). The expression of total DMBT1 (Santa Cruz Biotechnology, Inc.) in the stool samples of 325 subjects was measured via western blot analysis and optical densities (ODs; arbitrary units of DMBT1 immunoreactive signal) of blots were quantified using TINA software (version 2.10e; Raytest Isotopenmegerate $\mathrm{GmbH}$, Straubenhardt, Germany) after image scanning.

CRC tissue samples. Tissue microarray (TMA) blocks were constructed from formalin-fixed paraffin-embedded tissues of 385 patients with CRC who underwent surgical resection at the National Cancer Center of Korea (Goyang-si, Korea) from January 2003 to December 2003. One representative core tissue ( $2 \mathrm{~mm}$ in diameter) was taken from a paraffin block of each case and arranged in a new recipient paraffin block using a trephine apparatus (Superbiochips Laboratories, Seoul, Korea). Each TMA block contained one core of normal colorectal mucosal tissue (total number of normal tissues $=8$ ). Sections of $4 \mu \mathrm{m}$ in thickness were obtained from each TMA block for immunohistochemical analysis. Clinical charts and pathological reports of the 385 patients were reviewed. The tissue study population included 152 women and 231 men with a mean age of 58 years (range, 25-86 years) and follow-up time of 64 months (range, 2-74 months).

Immunohistochemistry. Immunohistochemical staining was performed using a BenchMark XT automated slide stainer (Ventana Medical Systems, Inc., Tucson, AZ, USA). De-waxing was implemented using the BenchMark module (Ventana Medical Systems, Inc.). Antigen retrieval was performed with Cell Conditioning solution 1/EDTA (pH 8.0) for $30 \mathrm{~min}$ at $98^{\circ} \mathrm{C}$ using the BenchMark staining module (Ventana Medical Systems, Inc.). Sections were incubated with mouse monoclonal anti-gp340 (5D7) antibody [conjugated with goat anti-mouse IgG H\&L HRP (cat. no. ab205719, 1:100, cat. no. ab17779; Abcam, Cambridge, UK)] for $40 \mathrm{~min}$ at $42^{\circ} \mathrm{C}$, and staining was performed on a Ventana Bench mark XT autostainer and evaluated with an I-View diaminobenzidine detection kit (both from Ventana Medical Systems, Inc.). Slides were counterstained with hematoxylin II for $4 \mathrm{~min}$ at room temperature and Bluing reagent (cat. no. 760-2037; Ventana Medical Systems, Inc.) for $4 \mathrm{~min}$ at room temperature. For the negative control, tissue sections were incubated with Trisbuffered saline alone without the primary antibody. DMBT1 expression was quantitatively evaluated using a double scoring system by estimating the staining intensity and percentage of stained cancer cells. The staining intensity was classified as 1 (weak), 2 (moderate) or 3 (strong). Immunoreactivity was scored as $0-300$ by multiplying the staining intensity by the percentage of cells stained. All immunohistochemical staining results were evaluated independently by two pathologists (HSP and HJC).

Statistical analysis. The OD values of DMBT1 expression levels in stool are expressed as the mean \pm standard

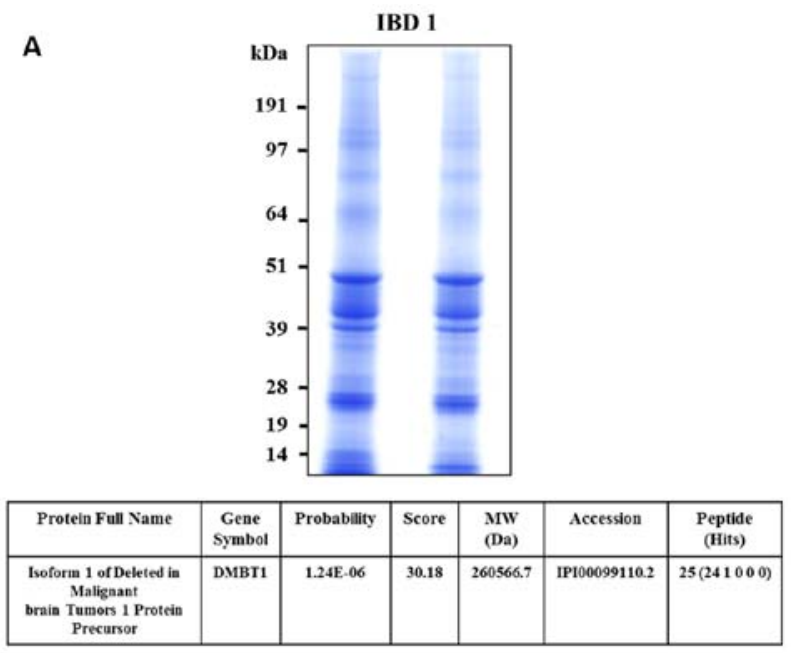

B

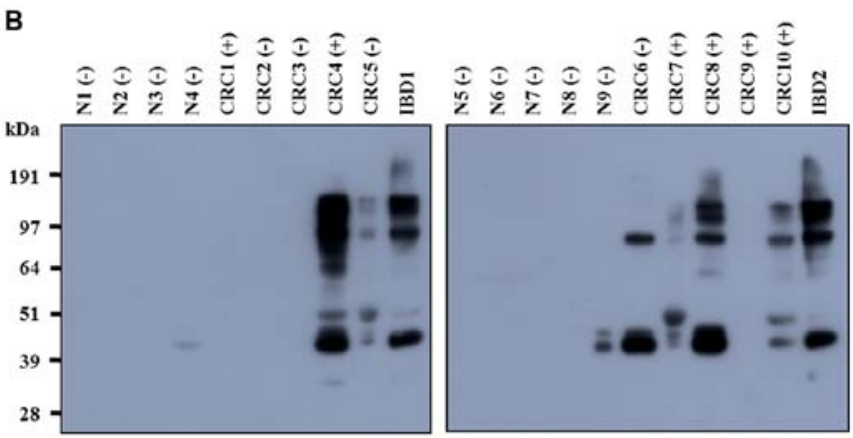

Figure 1. DMBT1 protein levels. (A) Stool extracts from IBD patients were separated via SDS-PAGE. Gel slices were excised, digested with trypsin and analyzed via LC-MS to determine the peptide mass. A SEQUEST database search led to the identification of isoform 1 of DMBT1. As in the harsh environment of stool, the protein was unlikely to be present in its intact form, fragments of DMBT1 were identified in most lanes of the SDS-PAGE gel. The molecular weight in the table is that of DMBT1 in its intact form. (B) Western blotting validating the upregulation of DMBT1 in the stool of IBD and CRC patients. Immunoreactive bands for DMBT1 indicate various fragmented forms in stool. DMBT1, deleted in malignant brain tumor 1 protein precursor; IBD, inflammatory bowel disease; LC-MS, liquid chromatography-mass spectrometry; $\mathrm{CRC}$, colorectal cancer; $\mathrm{N}$, normal control; MW, molecular weight.

deviation. One-way analysis of variance (ANOVA) and the $\chi^{2}$ test were used to compare DMBT1 levels among CRC, IBD, adenoma and control groups. In order to compare stool DMBT levels between two individual groups, one-way ANOVA was conducted, followed by a post-hoc Dunnett's test. The diagnostic potential of fecal DMBT1 was evaluated using receiver operator characteristics (ROC) curves, and the area under the ROC curve (AUC) was calculated. Cut-off values for each marker were determined from ROC and AUC values.

The $\chi^{2}$ test was additionally employed to evaluate the association between the expression of DMBT1 determined by immunohistochemical analysis and clinicopathological features. Overall or disease-free survival was estimated using the Kaplan-Meier method and compared with the log-rank test. The prognostic value of protein expression was determined via multivariate analysis using the Cox proportional hazards regression model. $\mathrm{P}<0.05$ was considered to indicate a statistically significant difference. All statistical analyses were performed using SPSS version 17.0 (SPSS Inc., Chicago, IL, USA). 
Table I. OD values of fecal DMBT1 protein precursor expression according to colorectal disease type.

\begin{tabular}{lccc}
\hline Groups & Test set & Validation set & Combined set \\
\hline Cancer & $(\mathrm{n}=81)^{\mathrm{a}, \mathrm{b}, \mathrm{e}}$ & $(\mathrm{n}=93)^{\mathrm{a}, \mathrm{b}, \mathrm{e}}$ & $(\mathrm{n}=174)^{\mathrm{a}, \mathrm{b}, \mathrm{e}}$ \\
& $945.48 \pm 1016.10$ & $1086.94 \pm 1161.10$ & $1021.09 \pm 1095.17$ \\
Adenoma & $(\mathrm{n}=32)^{\mathrm{e}}$ & $(\mathrm{n}=29)^{\mathrm{e}}$ & $(\mathrm{n}=61)^{\mathrm{e}}$ \\
& $310.79 \pm 603.17$ & $409.26 \pm 678.90$ & $357.60 \pm 636.80$ \\
IBD & $(\mathrm{n}=20)^{\mathrm{c}, \mathrm{d}}$ & $(\mathrm{n}=34)^{\mathrm{c}, \mathrm{d}}$ & $(\mathrm{n}=54)^{\mathrm{c}, \mathrm{d}}$ \\
& $914.61 \pm 905.93$ & $1079.90 \pm 1056.28$ & $1018.68 \pm 997.70$ \\
Control & $(\mathrm{n}=51)$ & $(\mathrm{n}=100)$ & $(\mathrm{n}=151)$ \\
& $268.57 \pm 603.03$ & $234.57 \pm 600.73$ & $246.05 \pm 599.72$ \\
& & & \\
\hline
\end{tabular}

${ }^{\mathrm{a}} \mathrm{P}<0.0001$ for cancer vs. normal; ${ }^{\mathrm{b}} \mathrm{P}<0.01$ cancer vs. adenoma; ${ }^{\mathrm{C}} \mathrm{P}<0.05$ for IBD vs. normal; ${ }^{\mathrm{d}} \mathrm{P}<0.05$ for IBD vs. adenoma, and ${ }^{\mathrm{e}} \mathrm{P}>0.05$ for cancer vs. IBD and adenoma vs. control in each set determined via a one-way analysis of variance test followed by a post-hoc Dunnett's test. ODs presented in arbitrary units of DMBT1 immunoreactive signal. Values are expressed as the mean \pm standard deviation. IBD, inflammatory bowel disease; DMBT1, deleted in malignant brain tumors $1, \mathrm{OD}$, optical density.

\section{Results}

LC-MS analysis of DMBT1 in stool samples of IBD and $C R C$ patients. Stool extracts from IBD patients were separated via SDS-PAGE. Gel slices were excised, digested with trypsin and analyzed using LC-MS to determine the peptide mass. A SEQUEST database search led to the identification of isoform 1 of DMBT1 (Fig. 1A). Upregulation of DMBT1 protein in stool samples of IBD and CRC patients relative to that in stool samples from healthy individuals was confirmed based on western blot analysis (Fig. 1B).

Fecal DMBTI expression in CRC, adenoma, IBD and control groups. The mean fecal DMBT1 protein expression was higher in patients with $\mathrm{CRC}$ than that in the healthy control $(\mathrm{P}<0.0001)$ and adenoma groups $(\mathrm{P}<0.0001)$ as well as higher in the IBD than in the healthy control $(\mathrm{P}<0.01)$ and adenoma groups $(\mathrm{P}<0.05)$. However, fecal DMBT1 levels were not significantly different between patients with IBD and CRC or adenoma and healthy controls in the test and validation sets $(\mathrm{P}>0.05)$. Similar results were obtained with the combined set (Table I).

The AUC value for fecal DMBT1 compared between the CRC and control groups was 0.684 . The cut-off value for DMBT1 per mg of stool protein was calculated as 1,224.0 OD. The proportion of patients positive for fecal DMBT1 was not significantly different among the subgroups of CRC patients according to CRC stage or site, or between advanced and non-advanced adenoma (Table II). The expression of fecal DMBT1 was also not different among the subgroups of IBD (Table II). The sensitivity of the fecal DMBT1 test for CRC, CRC+AA or CRC+AA+IBD was not high (48.9-50\%), while the specificity and positive predictive value (PPV) were moderate (specificity, 86.8\%; PPV, 81.3-85.3\% compared with the control; Table III).

Tissue expression of DMBT1 protein and clinicopathological correlation in CRC. In normal colorectal crypt epithelium, DMBT1 exhibited diffuse mild cytoplasmic
Table II. Number of patients with fecal DMBT1 expression (cut-off value of $\mathrm{OD}>1,224.05$ ) in each group of combinedset diseases.

\begin{tabular}{|c|c|c|c|c|}
\hline Pathology & $\mathrm{n}$ & $\begin{array}{c}\text { Positive cases } \\
(\mathrm{n}, \%)\end{array}$ & P-value ${ }^{b}$ & P-value ${ }^{f}$ \\
\hline $\begin{array}{l}\text { Cancer } \\
\text { pT stage }\end{array}$ & 174 & $87(50.0)$ & $<0.0001^{\mathrm{c}, \mathrm{e}}$ & \\
\hline $\mathrm{T} 1$ & 24 & $14(58.3)$ & & 0.537 \\
\hline $\mathrm{T} 2$ & 17 & 7 (38.9) & & \\
\hline $\mathrm{T} 3$ & 105 & $51(48.6)$ & & \\
\hline $\mathrm{T} 4$ & 27 & $15(55.6)$ & & \\
\hline \multicolumn{5}{|l|}{ Location } \\
\hline Right & 46 & $23(50.0)$ & & 1.000 \\
\hline Left & 128 & $64(50.0)$ & & \\
\hline $\mathrm{IBD}^{\mathrm{d}}$ & 54 & $27(50.0)$ & $0.970^{\mathrm{d}}$ & \\
\hline $\mathrm{UC}$ & 35 & $19(54.3)$ & & 0.693 \\
\hline $\mathrm{CD}$ & 12 & $5(41.7)$ & & \\
\hline Unclassified $^{\mathrm{a}}$ & 7 & $3(42.9)$ & & \\
\hline Adenoma $^{\mathrm{e}}$ & 61 & $14(23.0)$ & & \\
\hline AA & 8 & $2(25.0)$ & & 0.882 \\
\hline Non-AA & 53 & $12(22.6)$ & & \\
\hline Controls $^{\mathrm{c}}$ & 151 & $20(13.2)$ & & \\
\hline
\end{tabular}

${ }^{a}$ IBD, unclassified: IBD is clinically suspected but pathologic and endoscopic features are equivocal for the classification of ulcerative colitis or Crohn's disease (29). ${ }^{\text {b } C o m p a r i s o n ~ b e t w e e n ~ d i s e a s e ~ g r o u p s . ~}{ }^{\mathrm{c}}$ Cancer vs. control $(\mathrm{P}<0.0001) ;{ }^{\mathrm{d}}$ cancer vs. IBD $(\mathrm{P}=0.970) ;{ }^{\mathrm{e}}$ cancer vs. adenoma $(\mathrm{P}<0.0001)$; ${ }^{\mathrm{f}}$ comparison between intra-disease subtypes. DMBT1, deleted in malignant brain tumors 1; IBD, inflammatory bowel disease; UC, ulcerative colitis; $\mathrm{CD}$, Crohn's disease; AA, advanced adenoma; OD, optical density.

expression with an average immunoreactive score (IR) of 90; DMBT1 was also expressed in inflammatory cells infiltrating stroma (Fig. 2). In CRC cells, DMBT1 expression was increased or decreased (Fig. 2) with a mean IR value of 117.26 \pm 58.71 (range, 0-285). For the $\chi^{2}$ test, DMBT1 tissue expression was classified as follows: Group 1 (IR $\leq 10$ ), group 2 (IR $>10$ and $<150$ ) and group 3 (IR $\geq 150$ ). A total of 18 out of 385 tumors (4.7\%) were classified as group 1, $255(66.2 \%)$ as group 2 and $112(29.1 \%)$ as group 3. Group 1 (DMBT1 loss) was significantly associated with lymph node metastasis $(\mathrm{P}=0.016)$, distant metastasis $(\mathrm{P}=0.013)$, advanced stage $(\mathrm{P}=0.026)$ and higher histological grade $(\mathrm{P}=0.033)$. Conversely, group 3 (DMBT1 overexpression) was significantly associated with absence of lymph node metastasis (N0) or distant metastasis (M0), lower stage and low histological grade (Table IV).

Loss of DMBT1 expression and patient outcomes. Since group 1 (DMBT1 loss) was associated with adverse clinicopathological features, patients were subdivided into two groups according to their DMBT1 status (loss vs. no loss) for survival analysis. According to the univariate survival analysis, CRC patients with DMBT1 loss (group 1) had significantly shorter overall $(\mathrm{P}=0.005)$ and disease-free $(\mathrm{P}=0.001)$ survival than those without DMBT1 loss (groups 2 and 3; Table V; Fig. 3). 
Table III. Sensitivity, specificity and predictive value of fecal DMBT1 measurement for each group of combined-set diseases.

\begin{tabular}{|c|c|c|c|c|}
\hline Disease type of each patient & Sensitivity & Specificity & PPV & NPV \\
\hline CRC vs. controls & $87 / 174(50.0)$ & $131 / 151(86.8)$ & $87 / 107(81.3)$ & $131 / 218(60.1)$ \\
\hline $\mathrm{CRC}+\mathrm{AA}$ vs. controls & $89 / 182(48.9)$ & $131 / 151(86.8)$ & $89 / 109(81.7)$ & $131 / 224(58.5)$ \\
\hline $\mathrm{CRC}+\mathrm{AA}+\mathrm{IBD}$ vs. controls & $116 / 236(49.1)$ & $131 / 151(86.8)$ & $116 / 136(85.3)$ & $131 / 251(51.2)$ \\
\hline
\end{tabular}

Values are expressed as n/total (\%). Cutoff value for DMBT1 per mg of stool protein, 1,224.0 OD. CRC, colorectal cancer; AA, advanced adenoma; IBD, inflammatory bowel disease; PPV, positive predictive value; NPV, negative predictive value; DMBT1, deleted in malignant brain tumors 1 ; OD, optical density.
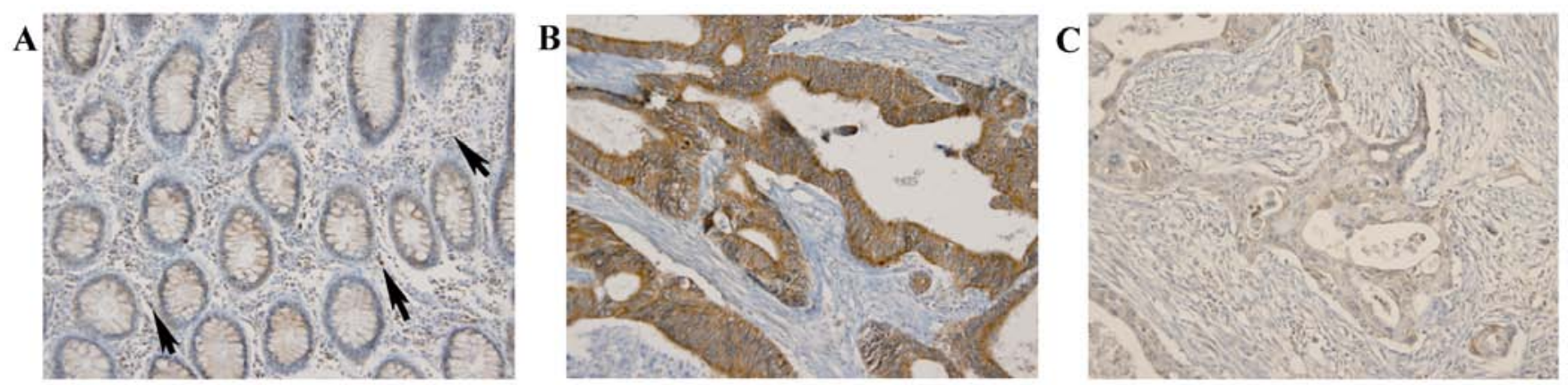

Figure 2. Representative immunohistochemical staining of DMBT1 protein in CRC (magnification, x200). (A) Normal colonic mucosa displayed diffuse mild cytoplasmic staining. Inflammatory cells (arrows) in lamina propria also indicated DMBT1 immunoreactivity. (B) DMBT1 protein expression was increased in $29.1 \%$ of the study population. (C) Loss of DMBT1 protein was detected in $4.7 \%$ of patients. DMBT1, deleted in malignant brain tumor 1 protein precursor; CRC, colorectal cancer.
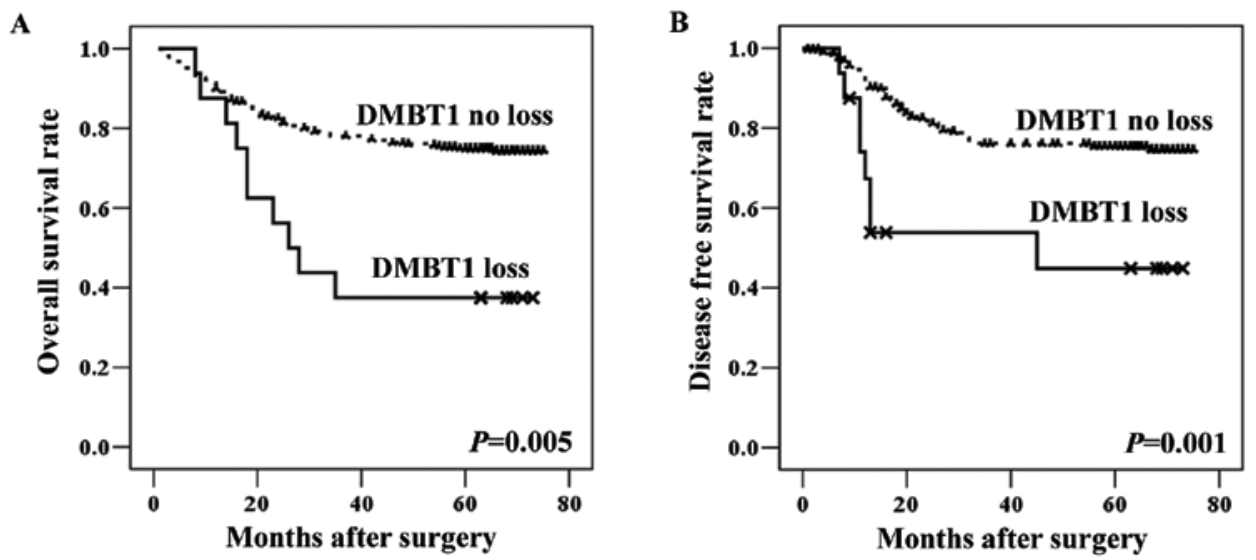

Figure 3. Kaplan-Meier survival curves for CRC patients stratified by their DMBT1 status. ' $x$ ' indicated events of mortality or recurrence. (A) Overall survival was measured from the date of surgery to the date of cancer-associated mortality or last follow-up. Loss of DMBT1 protein expression was significantly associated with poorer overall survival and (B) disease free survival, which was calculated from the date of surgery to the date of tumor recurrence/metastasis or last follow-up. DMBT1, deleted in malignant brain tumor 1 protein precursor; CRC, colorectal cancer.

According to the multivariate survival analysis (Table VI), loss of DMBT1 was an independent prognostic factor associated with poor overall survival (hazard ratio, 2.272; 95\% confidence interval, 1.175-4.391; $\mathrm{P}=0.015)$ and disease recurrence (hazard ratio, 2.689; 95\% confidence interval, 1.275-5.670; $\mathrm{P}=0.009$ ) in CRC patients after adjusting for stage, as well as venous, lymphatic and perineural invasion. Furthermore, the stage, as well as venous and perineural invasion were independent prognostic factors associated with overall and disease-free survival.

\section{Discussion}

DMBT1, a multifunctional glycoprotein containing multiple scavenger receptor cysteine-rich domains (9), is involved in the mucosal immune defense, epithelial differentiation (9-11) and tumor suppression (6). While loss of DMBT1 mRNA expression has been detected in various cancer types $(16,17)$, conflicting results have been reported by previous studies $(20,21)$. In an earlier study on colon cancer, a decrease in DMBT1 mRNA was reported in $16.7 \%$ of cancer compared with that in normal 
Table IV. DMBT1 expression in CRC tissues and its association with clinical and pathological factors $(n=385)$.

\begin{tabular}{|c|c|c|c|c|}
\hline \multirow[b]{2}{*}{ Characteristic } & \multicolumn{3}{|c|}{ DMBT1 expression } & \multirow[b]{2}{*}{ P-value } \\
\hline & $\mathrm{IRS} \leq 10$ & $10<\mathrm{IRS}<150$ & IRS $\geq 150$ & \\
\hline Sex & & & & 0.764 \\
\hline Male & $11(4.8)$ & $156(67.5)$ & $64(27.7)$ & \\
\hline Female & $7(4.5)$ & $99(64.3)$ & $48(31.2)$ & \\
\hline Age (years) & & & & 0.090 \\
\hline$<60$ & $14(6.8)$ & $137(66.2)$ & $56(27.1)$ & \\
\hline$\geq 60$ & $4(2.2)$ & $118(66.3)$ & $56(31.5)$ & \\
\hline T-stage & & & & 0.839 \\
\hline pT1,2 & $2(3.4)$ & $40(69.0)$ & $16(27.6)$ & \\
\hline pT3, 4 & $16(4.9)$ & 215 (65.7) & $96(29.4)$ & \\
\hline N-stage & & & & 0.016 \\
\hline pN0 & $3(1.9)$ & $101(63.1)$ & $56(35.0)$ & \\
\hline $\mathrm{pN} 1,2$ & $15(6.7)$ & $154(68.4)$ & $56(24.9)$ & \\
\hline M-stage & & & & 0.013 \\
\hline M0 & $8(2.9)$ & $184(65.9)$ & $87(31.2)$ & \\
\hline M1 & $10(9.4)$ & $71(67.0)$ & $25(23.6)$ & \\
\hline Stage & & & & 0.026 \\
\hline I, II & $3(2.0)$ & $95(62.9)$ & $53(35.1)$ & \\
\hline III, IV & $15(6.4)$ & $160(68.4)$ & $59(25.2)$ & \\
\hline $\begin{array}{l}\text { Venous } \\
\text { invasion }\end{array}$ & & & & 0.880 \\
\hline Absent & $11(4.4)$ & $167(67.1)$ & $71(28.5)$ & \\
\hline Present & $7(5.1)$ & $88(64.7)$ & $41(30.1)$ & \\
\hline $\begin{array}{l}\text { Lymphatic } \\
\text { invasion }\end{array}$ & & & & 0.476 \\
\hline Absent & $7(5.0)$ & $88(62.4)$ & $46(32.6)$ & \\
\hline Present & $11(4.5)$ & $167(68.4)$ & $66(27.0)$ & \\
\hline $\begin{array}{l}\text { Perineural } \\
\text { invasion }\end{array}$ & & & & 0.158 \\
\hline Absent & $10(3.8)$ & $172(64.7)$ & 84 (31.6) & \\
\hline Present & $8(6.7)$ & $83(69.7)$ & $28(23.5)$ & \\
\hline $\begin{array}{l}\text { Histological } \\
\text { grade }\end{array}$ & & & & 0.033 \\
\hline Low & $14(4.1)$ & 222 (64.9) & $106(31.0)$ & \\
\hline High & $4(9.3)$ & $33(76.7)$ & $6(14.0)$ & \\
\hline
\end{tabular}

Values are expressed as n (\%). DMBT1, deleted in malignant brain tumor 1; CRC, colorectal cancer; IRS, immunoreactive score; T, tumor; $\mathrm{N}$, node; $\mathrm{M}$, metastasis. Stages adapted from the American Joint Committee on Cancer TNM staging system, 6th edition (24).

tissue samples (17). However, the clinical validity of DMBT1 expression has not been evaluated in a large population of CRC patients.

In the present study, fecal DMBT1 expression was increased in patients with CRC, compared with that in the adenoma and control groups, but the levels were not significantly different from those of patients with IBD. In addition, DMBT1 expression was reported to be upregulated in neutrophils, monocytes and epithelial cells in IBD $(30,31)$. Upregulation of fecal
DMBT1 in CRC patients may be induced via interactions with cancer cells and microenvironments as well as immune reactions between epithelial and inflammatory cells. However, low levels of fecal DMBT1 in adenoma and control groups may be partly due to a less intense inflammatory reaction in adenoma or normal colorectal mucosal tissues, compared with that in CRC or IBD tissues. The results of the present study demonstrate that fecal DMBT1 is not effective for the differential diagnosis of CRC and IBD. However, a relatively high specificity (86.8\%) was observed for colorectal disease (CRC+AA+IBD) despite the low sensitivity (48.9-50.0\%).

Analysis of the clinical significance of DMBT1 expression in CRC tissues revealed that overexpression was more frequent than loss (29.1 vs. 4.7\%). Furthermore, expression of DMBT1 was significantly associated with absence of lymph node metastasis (N0) or distant metastasis (M0), lower stage and low histologic grade in CRC patients. A previous study by Conde et al (21) reported that DMBT1 protein expression is frequently decreased in well-differentiated adenocarcinoma of the stomach. These conflicting results on the expression patterns in gastric cancer vs. CRC tissues may be attributed to differences in the applied antibody, criteria for determining DMBT1 expression and organ specificity. In contrast to the present result that loss of DMBT1 expression is an independent prognostic factor associated with poor overall and disease-free survival of CRC patients, an earlier study revealed no clinicopathological significance of DMBT1 mRNA expression in esophageal cancer (17). The complex DMBT1 expression patterns in cancer are potentially associated with functional dualism, i.e., epithelial protection and differentiation (32). In early carcinogenesis, DMBT1 upregulation may provide an advantage for clonal expansion. At the late tumor stage, DMBT1 inactivation may be beneficial, since differentiation counteracts tumor progression. The present results suggest that loss of DMBT1 protein expression represents an effective biomarker for tumor progression in CRC. Consistent with the present observations, Goeppert et al (33) reported that increased DMBT1 protein expression was associated with prolonged overall survival in biliary tract cancer.

The present study has a number of limitations. First, analysis of fecal DMBT1 was inefficient as a screening test for CRC due to its low sensitivity. However, this drawback may be overcome by combined application with another complementary biomarker in the future. Furthermore, tissue and stool samples of enrolled CRC patients were different. Fecal DMBT1 represents protein secreted by cancer cells and the microenvironment. Consequently, the fecal DMBT1 measured did not originate from cancer cells alone but included a combination of proteins excreted from cancer cells as well as inflammatory cells. However, the tissue expression of DMBT1 was also measured in CRC tissues, which did not include any stromal or inflammatory cell components. DMBT1 expression was additionally identified in inflammatory cells infiltrating stroma (Fig. 2). Despite the study limitations, the present results clearly demonstrate that DMTB1 protein has a role in the progression of CRC and loss of expression in tissue is a promising prognostic marker for CRC patients.

In conclusion, the present study indicated that DMBT1 is upregulated in stools of CRC patients, while exhibiting 
Table V. Univariate survival analysis in CRC patients $(n=385)$.

\begin{tabular}{|c|c|c|c|c|c|c|}
\hline \multirow[b]{2}{*}{ Variables } & \multicolumn{3}{|c|}{ Overall survival (months) } & \multicolumn{3}{|c|}{ Disease-free survival (months) } \\
\hline & Mean & $95 \% \mathrm{CI}$ & P-value & Mean & $95 \% \mathrm{CI}$ & P-value \\
\hline Sex & & & 0.6842 & & & 0.0483 \\
\hline Male & 60 & $56-63$ & & 63 & $59-66$ & \\
\hline Female & 60 & $56-64$ & & 56 & $52-61$ & \\
\hline Age (years) & & & 0.1964 & & & 0.6238 \\
\hline$<60$ & 61 & $58-64$ & & 59 & $55-63$ & \\
\hline$\geq 60$ & 58 & $54-62$ & & 61 & $57-65$ & \\
\hline Stage & & & $<0.0001$ & & & $<0.0001$ \\
\hline I and II & 73 & $71-74$ & & 70 & $68-73$ & \\
\hline III and IV & 52 & $48-56$ & & 52 & $48-56$ & \\
\hline Histological grade & & & 0.0052 & & & 0.3271 \\
\hline Low & 61 & $59-64$ & & 61 & $58-63$ & \\
\hline High & 49 & $40-58$ & & 55 & $46-65$ & \\
\hline Venous invasion & & & $<0.0001$ & & & $<0.0001$ \\
\hline Absent & 67 & $65-70$ & & 68 & $65-70$ & \\
\hline Present & 46 & $41-51$ & & 42 & $36-48$ & \\
\hline Lymphatic invasion & & & $<0.0001$ & & & $<0.0001$ \\
\hline Absent & 70 & $67-72$ & & 68 & $65-71$ & \\
\hline Present & 55 & $51-58$ & & 55 & $51-59$ & \\
\hline Perineural invasion & & & $<0.0001$ & & & $<0.0001$ \\
\hline Absent & 66 & $63-68$ & & 66 & $64-69$ & \\
\hline Present & 48 & $42-53$ & & 43 & $37-49$ & \\
\hline DMBT1 expression & & & 0.0050 & & & 0.0010 \\
\hline No loss & 61 & $58-64$ & & 61 & $58-64$ & \\
\hline Loss & 40 & $26-53$ & & 42 & $27-52$ & \\
\hline
\end{tabular}

CI, confidence interval; DMBT1, deleted in malignant brain tumor 1; CRC, colorectal cancer.

Table VI. Multivariate survival analysis in CRC patients $(n=385)$.

\begin{tabular}{|c|c|c|c|c|c|c|}
\hline \multirow[b]{2}{*}{ Variables } & \multicolumn{3}{|c|}{ Overall survival } & \multicolumn{3}{|c|}{ Disease-free survival } \\
\hline & HR & $95 \% \mathrm{CI}$ & P-value & HR & $95 \% \mathrm{CI}$ & $\mathrm{P}$-value \\
\hline \multicolumn{7}{|l|}{ Stage $^{\mathrm{a}}$} \\
\hline I, II vs. III, IV & 5.604 & $2.480-12.664$ & $<0.0001$ & 2.119 & $1.075-4.176$ & 0.030 \\
\hline \multicolumn{7}{|l|}{ Venous invasion } \\
\hline Absent vs. present & 2.220 & $1.426-3.455$ & $<0.0001$ & 2.900 & $1.745-4.821$ & $<0.001$ \\
\hline \multicolumn{7}{|l|}{ Lymphatic invasion } \\
\hline Absent vs. present & 1.638 & $0.934-2.872$ & 0.085 & 1.548 & $0.864-2.773$ & 0.142 \\
\hline \multicolumn{7}{|l|}{ Perineural invasion } \\
\hline Absent vs. present & 1.557 & $1.021-2.374$ & 0.040 & 2.347 & $1.457-3.781$ & $<0.001$ \\
\hline \multicolumn{7}{|l|}{ DMBT1 expression } \\
\hline No loss vs. loss & 2.272 & $1.175-4.391$ & 0.015 & 2.689 & $1.275-5.670$ & 0.009 \\
\hline
\end{tabular}

variable expression in CRC tissues. Loss of DMBT1 protein in CRC tissues is significantly associated with adverse clinicopathological features (advanced stage, lymph node or distant metastasis and high histological grade) and may be 
effectively utilized as an independent poor prognostic factor for CRC.

\section{Acknowledgements}

Not applicable.

\section{Funding}

This study was supported by a grant from the National Cancer Centre of Korea (grant no. NCC-1710880).

\section{Availability of data and materials}

The datasets used and/or analyzed during the present study are available from the corresponding author on reasonable request.

\section{Authors' contributions}

HSP, BCK and HJC collected and analyzed the data, and drafted the manuscript. HJC provided analytical oversight; HJC designed and supervised the study. HSP, BCK, HJC, HYY, KHK, BCY and JWP revised the manuscript for important intellectual content; HYY, KHK, BCY and JWP provided administrative support. All authors have read and approved the final version to be published.

\section{Ethical approval and consent to participate}

Informed consent was obtained from all enrolled patients. The protocol of the present study was reviewed and approved by the Institutional Review Board of National Cancer Center (nos. NCCNTS-08-351 and -354; Goyang-si, Korea).

\section{Consent for publication}

Not applicable.

\section{Competing interests}

The authors declare that they have no competing interests.

\section{References}

1. Ferlay J, Soerjomataram I, Dikshit R, Eser S, Mathers C, Rebelo M, Parkin DM, Forman D and Bray F: Cancer incidence and mortality worldwide: Sources, methods and major patterns in GLOBOCAN 2012. Int J Cancer 136: E359-E386, 2015.

2. Jung KW, Won YJ, Oh CM, Kong HJ, Lee DH and Lee KH; Community of Population-Based Regional Cancer Registries: Cancer Statistics in Korea: Incidence, mortality, survival, and prevalence in 2014. Cancer Res Treat 49: 292-305, 2017.

3. Rhodes JM: Colorectal cancer screening in the UK: Joint position statement by the British Society of Gastroenterology, The Royal College of Physicians, and The Association of Coloproctology of Great Britain and Ireland. Gut 46: 746-748, 2000.

4. Kim BC, Joo J, Chang HJ, Yeo HY, Yoo BC, Park B, Park JW, Sohn DK, Hong CW and Han KS: A predictive model combining fecal calgranulin B and fecal occult blood tests can improve the diagnosis of colorectal cancer. PLoS One 9: e106182, 2014.

5. Yoo BC, Shin YK, Lim SB, Hong SH, Jeong SY and Park JG: Evaluation of calgranulin B in stools from the patients with colorectal cancer. Dis Colon Rectum 51: 1703-1709, 2008.
6. Mollenhauer J, Wiemann S, Scheurlen W, Korn B, Hayashi Y, Wilgenbus KK, von Deimling A and Poustka A: DMBT1, a new member of the SRCR superfamily, on chromosome 10q25.3-26.1 is deleted in malignant brain tumours. Nat Genet 17: 32-39, 1997.

7. Ligtenberg TJ, Bikker FJ, Groenink J, Tornoe I, Leth-Larsen R, Veerman EC, Nieuw Amerongen AV and Holmskov U: Human salivary agglutinin binds to lung surfactant protein-D and is identical with scavenger receptor protein gp-340. Biochem J 359: 243-248, 2001.

8. Ligtenberg AJ, Karlsson NG and Veerman EC: Deleted in malignant brain tumors-1 protein (DMBT1): A pattern recognition receptor with multiple binding sites. Int J Mol Sci 11: 5212-5233, 2010

9. Madsen J, Mollenhauer J and Holmskov U: Review: Gp-340/DMBT1 in mucosal innate immunity. Innate Immun 16: 160-167, 2010.

10. Vijayakumar S, Takito J, Hikita C and Al-Awqati Q: Hensin remodels the apical cytoskeleton and induces columnarization of intercalated epithelial cells: Processes that resemble terminal differentiation. J Cell Biol 144: 1057-1067, 1999.

11. Cheng H, Bjerknes M and Chen H: CRP-ductin: A gene expressed in intestinal crypts and in pancreatic and hepatic ducts. Anat Rec 244: 327-343, 1996

12. Holmskov U, Mollenhauer J, Madsen J, Vitved L, Gronlund J, Tornoe I, Kliem A, Reid KB, Poustka A and Skjodt K: Cloning of gp-340, a putative opsonin receptor for lung surfactant protein D. Proc Natl Acad Sci USA 96: 10794-10799, 1999.

13. Madsen J, Sorensen GL, Nielsen O, Tornøe I, Thim L, Fenger C, Mollenhauer J and Holmskov U: A variant form of the human deleted in malignant brain tumor 1 (DMBT1) gene shows increased expression in inflammatory bowel diseases and interacts with dimeric trefoil factor 3 (TFF3). PLoS One 8: e64441, 2013.

14. Garay J, Piazuelo MB, Lopez-Carrillo L, Leal YA, Majumdar S, Li L, Cruz-Rodriguez N, Serrano-Gomez SJ, Busso CS, Schneider BG, et al: Increased expression of deleted in malignant brain tumors (DMBT1) gene in precancerous gastric lesions: Findings from human and animal studies. Oncotarget 8 : 47076-47089, 2017.

15. Mollenhauer J, Holmskov U, Wiemann S, Krebs I, Herbertz S, Madsen J, Kioschis P, Coy JF and Poustka A: The genomic structure of the DMBT1 gene: Evidence for a region with susceptibility to genomic instability. Oncogene 18: 6233-6240, 1999.

16. Wu W, Kemp BL, Proctor ML, Gazdar AF, Minna JD, Hong WK and Mao L: Expression of DMBT1, a candidate tumor suppressor gene, is frequently lost in lung cancer. Cancer Res 59: 1846-1851, 1999.

17. Mori M, Shiraishi T, Tanaka S, Yamagata M, Mafune K, Tanaka Y, Ueo H, Barnard GF and Sugimachi K: Lack of DMBT1 expression in oesophageal, gastric and colon cancers. Br J Cancer 79: 211-213, 1999.

18. Braidotti P, Nuciforo PG, Mollenhauer J, Poustka A, Pellegrini C, Moro A, Bulfamante G, Coggi G, Bosari S and Pietra GG: DMBT1 expression is down-regulated in breast cancer. BMC Cancer 4: 46, 2004.

19. Mueller W, Mollenhauer J, Stockhammer F, Poustka A and von Deimling A: Rare mutations of the DMBT1 gene in human astrocytic gliomas. Oncogene 21: 5956-5959, 2002.

20. Mollenhauer J, Herbertz S, Holmskov U, Tolnay M, Krebs I, Merlo A, Schrøder HD, Maier D, Breitling F, Wiemann S, et al: DMBT1 encodes a protein involved in the immune defense and in epithelial differentiation and is highly unstable in cancer. Cancer Res 60: 1704-1710, 2000.

21. Conde AR,Martins AP,Brito M,Manuel A,Ramos S, Malta-Vacas J, Renner M, Poustka A, Mollenhauer J and Monteiro C: DMBT1 is frequently downregulated in well-differentiated gastric carcinoma but more frequently upregulated across various gastric cancer types. Int J Oncol 30: 1441-1446, 2007.

22. Mollenhauer J, Helmke B, Müller H, Kollender G, Lyer S, Diedrichs L, Holmskov U, Ligtenberg T, Herbertz S, Krebs I, et al: Sequential changes of the DMBT1 expression and location in normal lung tissue and lung carcinomas. Genes Chromosomes Cancer 35: 164-169, 2002.

23. World Health Organization: WHO Classification of Tumours of the Digestive System. Bosman FT, Carneiro F, Hruban RH and Theise ND (eds). Vol 3, 4th edition. IARC, Lyon, 2010.

24. American Joint Committee on Cancer: AJCC Cancer Staging Atlas. Greene FL, Compton CC, Fritz AG, Shah JP, Winchester DP (eds). Springer, New York, 2006. doi: org/10.1007/0-387-33126-3. 
25. Lieberman DA, Weiss DG, Bond JH, Ahnen DJ, Garewal H and Chejfec G: Use of colonoscopy to screen asymptomatic adults for colorectal cancer. Veterans Affairs Cooperative Study Group 380. N Engl J Med 343: 162-168, 2000.

26. Yao T, Matsui T and Hiwatashi N: Crohn's disease in Japan: Diagnostic criteria and epidemiology. Dis Colon Rectum 43 (Suppl): S85-S93, 2000.

27. Choi CH, Jung SA, Lee BI, Lee KM, Kim JS and Han DS; IBD Study Group of the Korean Association of the Study of Intestinal Diseases: Diagnostic guideline of ulcerative colitis. Korean J Gastroenterol 53: 145-160, 2009 (In Korean).

28. Ye BD, Jang BI, Jeen YT, Lee KM, Kim JS and Yang SK; IBD Study Group of the Korean Association of the Study of Intestinal Diseases: Diagnostic guideline of Crohn's disease. Korean J Gastroenterol 53: 161-176, 2009 (In Korean).

29. Telakis E and Tsironi E: Indeterminate colitis-definition, diagnosis, characteristics and management. Ann Gastroenterol 21: 173-180, 2009
30. Foell D, Wittkowski H and Roth J: Monitoring disease activity by stool analyses: From occult blood to molecular markers of intestinal inflammation and damage. Gut 58: 859-868, 2009.

31. Rosenstiel P, Sina C, End C, Renner M, Lyer S, Till A, Hellmig S, Nikolaus S, Fölsch UR, Helmke B, et al: Regulation of DMBT1 via NOD2 and TLR4 in intestinal epithelial cells modulates bacterial recognition and invasion. J Immunol 178: 8203-8211, 2007.

32. Mollenhauer J, Helmke B, Müller H, Kollender G, Krebs I, Wiemann S, Holmskov U, Madsen J, Otto HF and Poustka A: An integrative model on the role of DMBT1 in epithelial cancer. Cancer Detect Prev 26: 266-274, 2002.

33. Goeppert B, Roessler S, Becker N, Zucknick M, Vogel MN, Warth A, Pathil-Warth A, Mehrabi A, Schirmacher P, Mollenhauer J, et al: DMBT1 expression in biliary carcinogenesis with correlation of clinicopathological data. Histopathology 70: 1064-1071, 2017 